\title{
Moisture diagnostic of a failured roof drainage situated behind a parapet wall and a subsequent condensate influence to a wooden construction
}

\author{
Josef Remeš ${ }^{1, *}$, Roman Brzoň ${ }^{1}$, Tomáš Petř́íček ${ }^{1}$, and Jiř́ Horák ${ }^{1}$ \\ ${ }^{1}$ BUT, Faculty of Civil Engineering, Veveř́ 331/95, 60200 Brno, Czech Republic
}

\begin{abstract}
There are several possibilities how to deal with a roof drainage. From an architectonic point of view an improper and unsuitable system is chosen in a majority of cases which may be as a logical consequence the beginning of upcoming problems. One of these problems is typically connected with either a roof location near the parapet wall, or in the corner of a flat roof. Another one is generally represented by a roof drainage solution with a side inflow for the drainage system that goes through the parapet wall construction. This solution is represented by a useful space increase in a layout of the building and an installation of a rainwater drainage core is not necessary in such cases. In case more of negative effects accumulate, such as an improper thermal insulation quality or insufficient thickness of the thermal insulation, significant problems may appear hand in hand with using of the building. These problems are generally represented by a moisture appearance in the inflow area. What more, this is not always detected and a major cause can be determined very hardly. This article deals with possible solutions for the wooden construction failure caused by the moisture that may emerge as an improper inflow layout consequence.
\end{abstract}

\section{Introduction}

Ambient humidity condensation may appear in almost any building type. If this kind of humidity appears only for a short period of time (e.g. during cooking time) there is no need to deal with this issue as it evaporates soon after. On contrary if there is either a long-term or extensive humidity a certain problem may appear. Humidity may bring degradation to the surface layers of plater or constructions. In this case ambient humidity condensation was related to a house where humidity maps started to appear due to an improper inflow layout and a combination of other influencing factors and as a subsequence adequate house living was not enabled [1-4].

\footnotetext{
* Corresponding author: remes.j@,fce.vutbr.cz
} 


\subsection{Building description}

The building is considered for living and occupied by five users. There is a 2-floor detached house situated in a north-east part of the municipality. The building is a composition of two mass in a rectangular shape. The first part consists of two-flow section roofed with a flat mono-pitched roof which is drained to a parapet wall. The parapet wall is subsequently led to the one-floor area roof. The one-floor part roof is a flat roof loaded by pea gravel, drained by two roof drains which are situated above a living room and bedroom of the house.

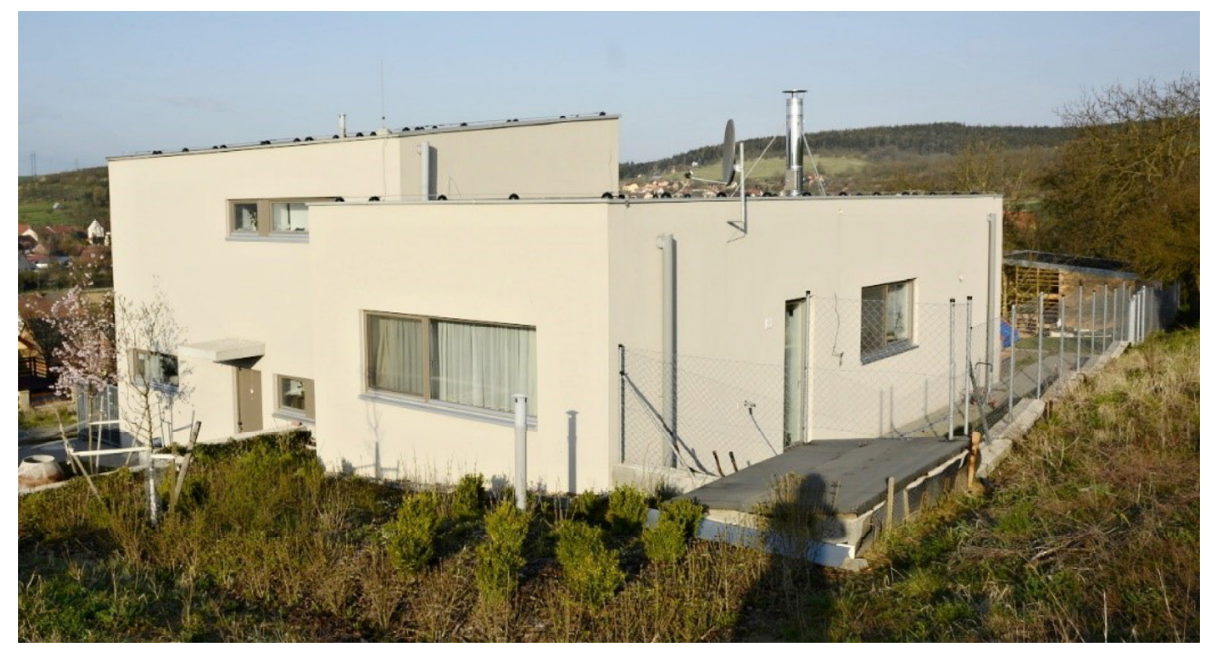

Fig. 1. Elevation at building.

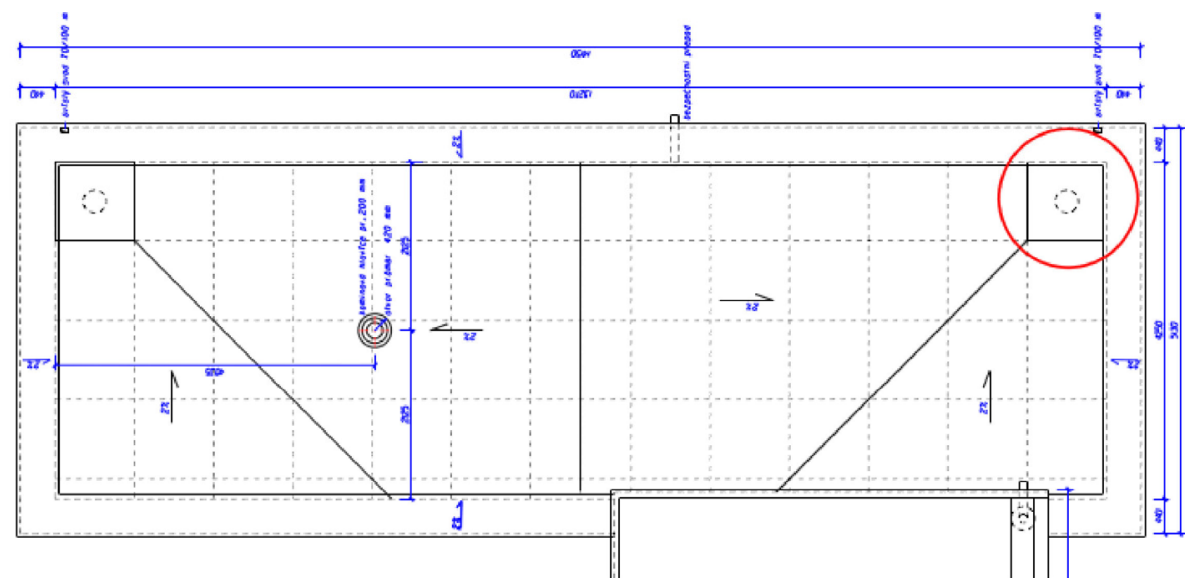

Fig. 2. Roof plan. 


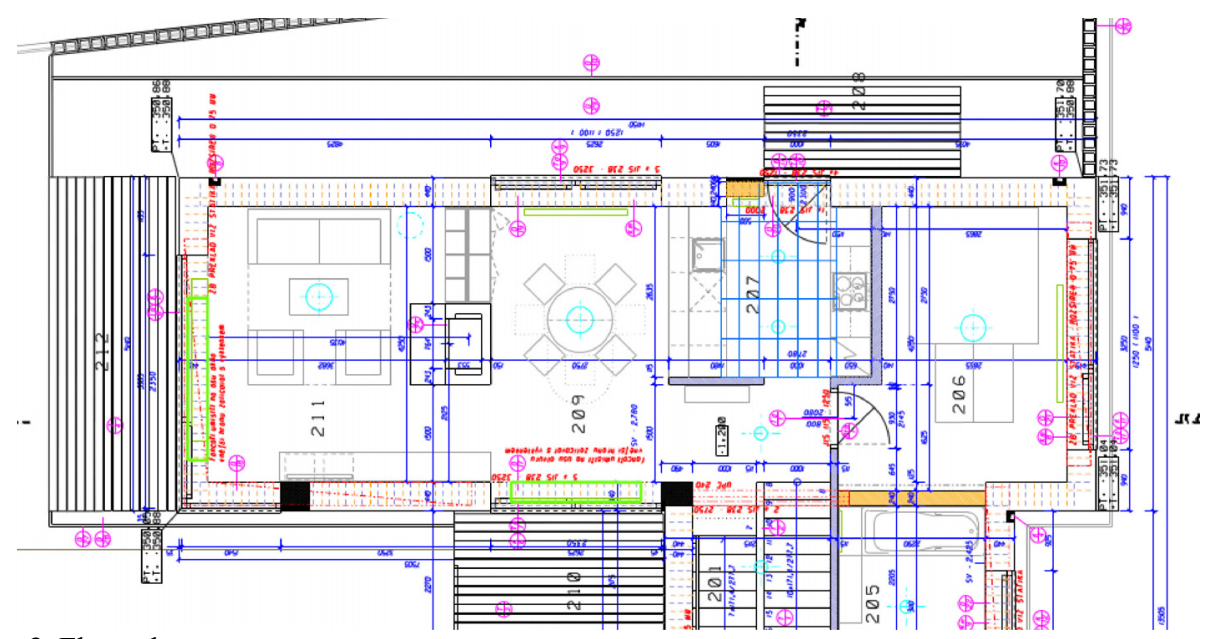

Fig. 3. Floor plan.

\subsection{Construction description}

Affected one-floor construction is covered by a flat roof loaded by a pea gravel drained by heated horizontal roof drains throughout the parapet wall construction into the vertical drainage situated on an outer part of a facade. Vertical construction is built from perforated blocks. Load-bearing structure of the roof consists of $160 \times 220 \mathrm{~mm}$ beam system with OSB slab formwork where following roof composition is used:

- Loading by a pea gravel,

- mPVC hydroisolation,

- Screed to fall from heat isolation made by EPS slabs,

- Geofabric,

- Moisture barrier from light type folio,

- OSB slab framework.

\section{Condensation}

Water vapour condensation started to appear during season with external temperature around $0-4{ }^{\circ} \mathrm{C}$ with a foggy climate, or higher external humidity. Condensation was evident via humidity maps on a lower front side of OSB slab framework above the living room and bedroom. Furthermore, during the critical season humidity maps were followed by a drop leakage into the interior with capacity of 1 deciliter á $6 \mathrm{~h}$.

\subsection{Searching for the root cause}

First the root cause might have been found in leakage of hydroisolation folio connection. During the research and inspection was possible to identify that the folio connection is in a good condition. Next a probe into the roof construction was used in order to clarify if there is any extreme water vapour and heat isolation moisture on the moisture barrier interface. The probe did not give any proof of a higher level of heat isolation moisture. On the other hand, it showed that the roof drains had not been in function and in the cabel area, which enables roof drain supply, sufficient sealing and connection to the moisture barrier was not carried out. In addition, discrepancy with design documentation was revealed when a heat 
isolation with noticeably higher thermal-technical properties should have been applied under the roof drain. Besides, roof draines were clogged by soil and due to insufficient screed to fall the water was kept locally in depressed area of a drainage and connection of a roof drain with horizontal internal (rainwater) drainage.

Based on these findings change of roof drains was performed as well as a sealing of cabel pass through by an aluminium tape designed for moisture barrier repair. Unfortunately, after six months condensation repeated in a similar range again.

After this condensation root cause needed to be revealed. It was necessary to consider possibility of moisture distribution in bad aired air layer going consequently above the living room, kitchen and bedroom. It was also necessary to take into account possibility of moisture appearance in cool corner due to insufficiently solved details with inadequate thermoisolation.

\subsection{Measuring and diagnostics}

Moisture measuring, screening by infra camera and modelling of chosen constructions in simulation software was used in order to identify the moisture source.

\subsubsection{Thermografical measuring}

Critical temperature is evident in the themogram. The temperature difference between an edge and corner of ceiling construction is obvious. Following temperature was recorded during border condition:

- Interior temperature: $22{ }^{\circ} \mathrm{C}$,

- Interior relative humidity: $55 \%$,

- Exterior temperature: $+5^{\circ} \mathrm{C}$,

- Exterior relative humidity: $75 \%$.
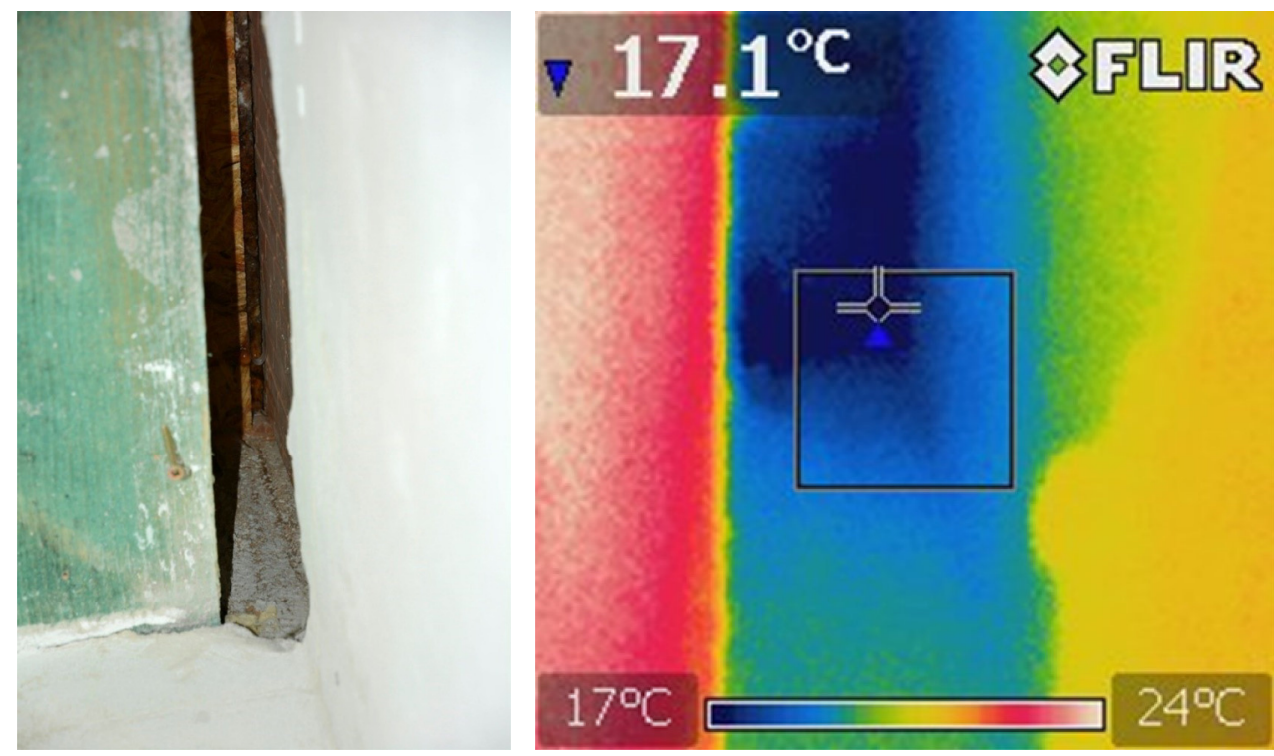

Fig. 4. Thermografical screening of the hollow on the interface of beam and circumferential construction (bedroom).

Dew point temperature is during this condition $15.992^{\circ} \mathrm{C}$. The temperature was almost reached and even though the exterior border condition was really advantageous. 


\subsubsection{Moisture measuring}

Relative humidity between the beam and view from below and temperature of few areas was measured in order to determine moisture.

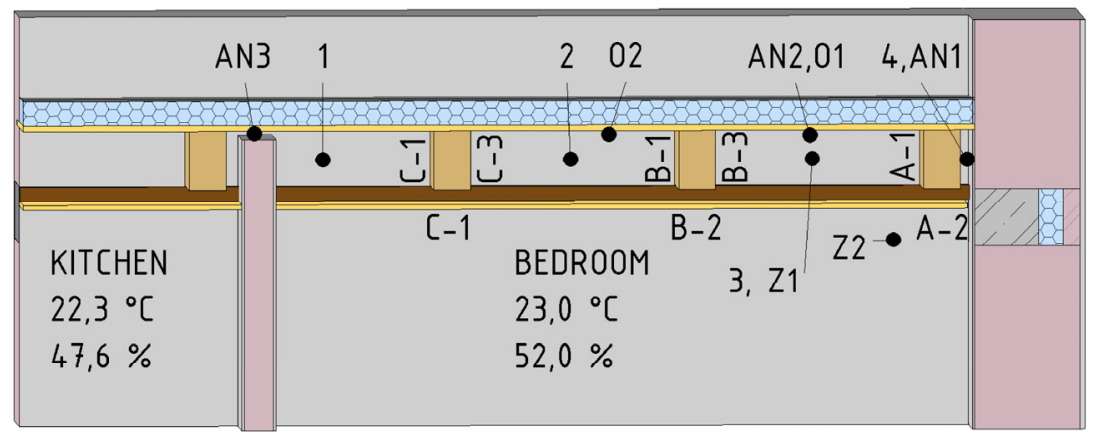

Fig. 5. Measuring points position.

Measuring was performed by MOIST device and the moisture of approximately 20$35 \%$ was shown. Based on the calibration curves, which had been specified during previous measuring, this moisture responds to the $10 \%$ spruce wood volume humidity. This can be considered as a normal moisture of build-in wood and is not a sign of significant surface condensation yet.

\subsection{3 $2 D$ detail in thermal field}

Actual 2D modelling of critical area during local border conditions was used. Applied isotherm represents critical temperature development. In an interruption area this requirement is underestimated which brings water condensation. Water vapour condensation is even higher in the roof area, which is weakened in the roof catch basin.

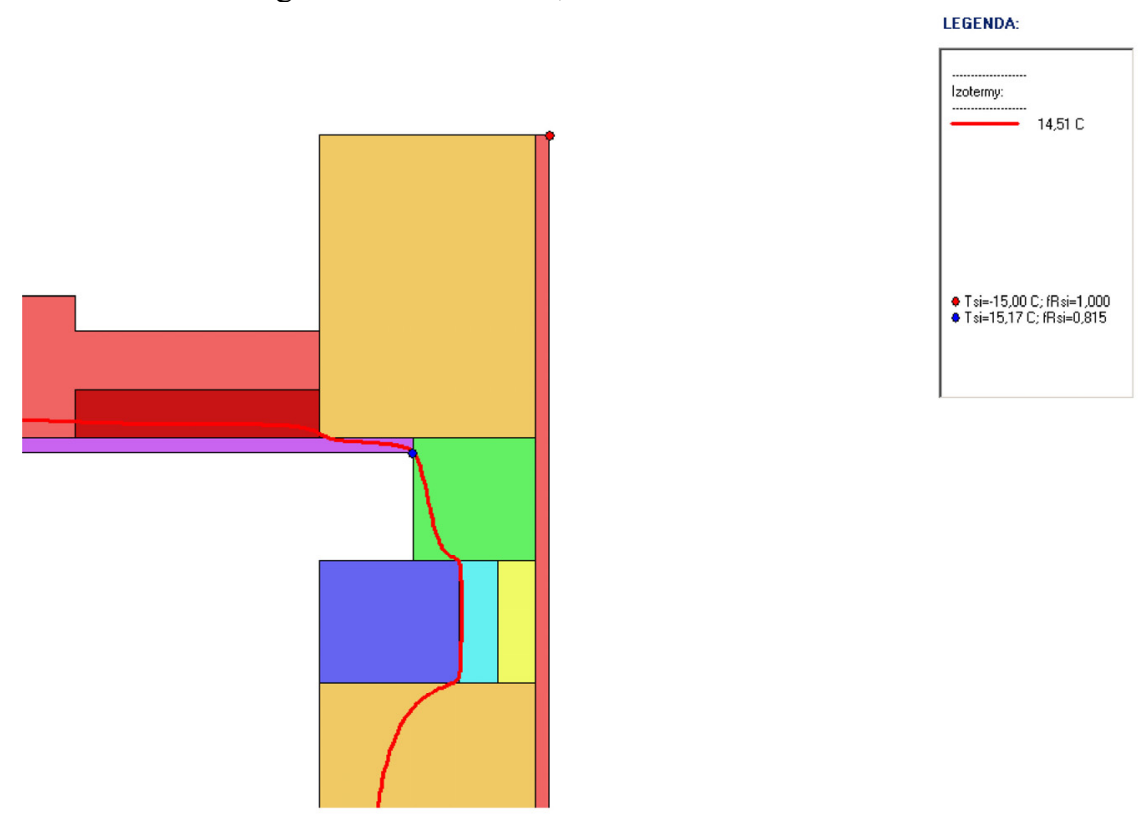

Fig. 6. Critical corner 2D modelling. 


\subsubsection{Flow simulation by CFD}

In order to take into consideration a moisture occurence due to a distribution in bad aired air layer a simulation of CFD (Computational Fluid Dynamics) was used to examine real flow in the building in comparison with real measuring on the site. Thanks to the simulation it was possible to exclude significant influence of redistribution of moisture from neighbouring rooms.
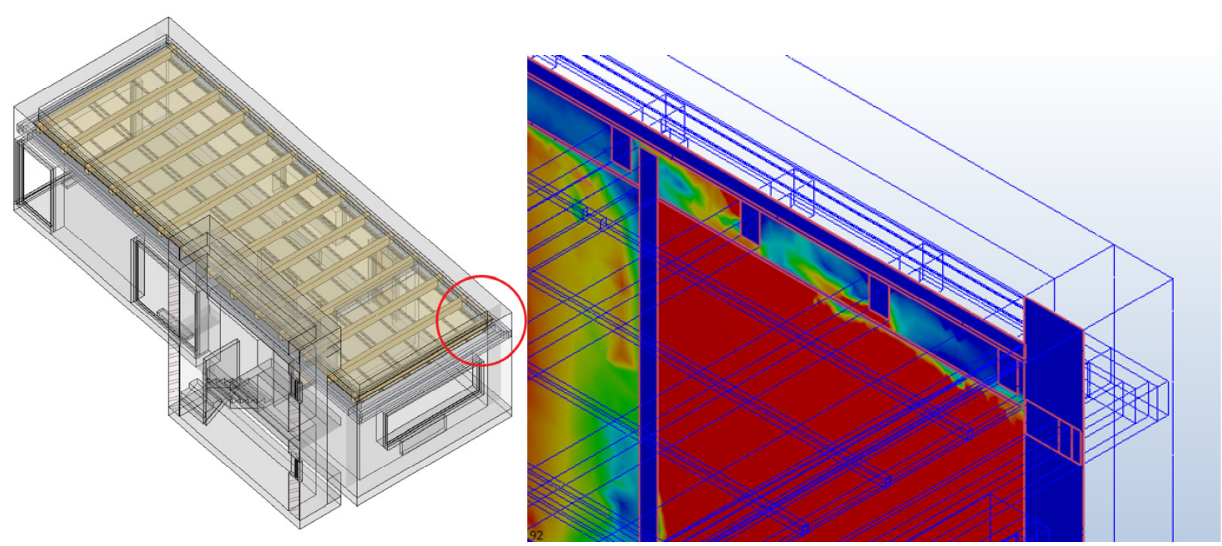

Fig. 7. Area and output example from CFD simulation.

\section{Summary}

Affected roof construction consists of moisture barrier designed as light type folio which is neither standard nor recommended solution as the diffusion resistance is not as high as in case of heavy asphalt membrane and it is easier to perforate this layer. Base layer of moisture barrier layer consists of OSB slab, which is not sufficiently sealed with circumferencial vertical bearing construction and thus the arisen hollow brings higher air moisture level. In this hollow high relative moisture was measured (approximately 55\%) in case the view from below was opened. During its closure even higher moisture is highly to be expected.

Based on measured values, performed simulations and actual situation analysis it is obvious that the condensation and leakage problems are caused by weakening (lowering of thickness) of themoisolation building cover in roof drainage area. The main function of this isolation is to minimize thermal bridge occurance and decrease surface condensation risk. Weakening has significant influence on surface temperature as well as surface condensation occurance. This impact is multiplied by the fact that under the roof drainage a thermal isolation with low thermal conductivity coefficient was chosen.

Damage of moister barrier layer and in general insufficient detail conception of its connection may negatively contribute to higher condensation inside of the construction in drainage area and then condensate return into the interior. These high-risk areas appear in this building fully logically near drainage fastening, alternatively in connection of the moisture barrier to parapet wall. 


\section{References}

1. ČSN EN ISO 10211 Thermal bridges in building construction - Heat flows and surface temperatures - Detailed calculations (2009)

2. C C SN 73 0540-2 Thermal protection of buildings - Part 2: Requirements (2011)

3. ČSN 73 0540-3 Thermal protection of buildings - Part 3: Design value quantities (2005)

4. K. Chaloupka, Z. Svoboda, Ploché střechy: Praktický průvodce (Prague, Grada Publishing, 2009) 